\title{
Article \\ Genome-wide Analysis of Basic Helix-Loop-Helix Family Genes and Expression Analysis in Response to Drought and Salt Stresses in Hibiscus hamabo Sieb. et Zucc
}

\author{
Longjie Ni $^{1,2}$, Zhiquan Wang ${ }^{2}$, Zekai Fu ${ }^{1}$, Dina Liu ${ }^{1}$ (D), Yunlong Yin ${ }^{2,3}$, Huogen Li ${ }^{1, *(D)}$ and Chunsun Gu ${ }^{1,2,3, *}$ \\ 1 College of Forest Sciences, Nanjing Forestry University, Nanjing 210037, China; LongJieNi@njfu.edu.cn (L.N.); \\ fzk@njfu.edu.cn (Z.F.); cc0212@njfu.edu.cn (D.L.) \\ 2 Institute of Botany, Jiangsu Province and Chinese Academy of Sciences, Nanjing 210014, China; \\ wangzhiquan@cnbg.net (Z.W.); ylyin@cnbg.net (Y.Y.) \\ 3 Jiangsu Key Laboratory for the Research and Utilization of Plant Resources, Jiangsu Provincial Platform for \\ Conservation and Utilization of Agricultural Germplasm, Nanjing 210014, China \\ * Correspondence: hgli@njfu.edu.cn (H.L.); chunsungu@cnbg.net (C.G.)
}

check for

updates

Citation: Ni, L.; Wang, Z.; Fu, Z.; Liu,

D.; Yin, Y.; Li, H.; Gu, C.

Genome-wide Analysis of Basic

Helix-Loop-Helix Family Genes and

Expression Analysis in Response to

Drought and Salt Stresses in Hibiscus hamabo Sieb. et Zucc. Int. J. Mol. Sci.

2021, 22, 8748. https://doi.org/

$10.3390 /$ ijms 22168748

Academic Editor: Bartolome Sabater

Received: 22 May 2021

Accepted: 7 August 2021

Published: 15 August 2021

Publisher's Note: MDPI stays neutral with regard to jurisdictional claims in published maps and institutional affiliations.

Copyright: (c) 2021 by the authors. Licensee MDPI, Basel, Switzerland. This article is an open access article distributed under the terms and conditions of the Creative Commons Attribution (CC BY) license (https:/ / creativecommons.org/licenses/by/ $4.0 /)$.

\begin{abstract}
The basic helix-loop-helix (bHLH) family of transcription factors is one of the most significant and biggest in plants. It is involved in the regulation of both growth and development, as well as stress response. Numerous members of the bHLH family have been found and characterized in woody plants in recent years. However, no systematic study of the $b H L H$ gene family has been published for Hibiscus hamabo Sieb. et Zucc. In this research, we identified $162 \mathrm{bHLH}$ proteins (HhbHLHs) from the genomic and transcriptomic datasets of H. hamabo, which were phylogenetically divided into 19 subfamilies. According to a gene structural study, the number of exon-introns in HhbHLHs varied between zero and seventeen. MEME research revealed that the majority of HhbHLH proteins contained three conserved motifs, 1, 4, and 5. The examination of promoter cis-elements revealed that the majority of HhbHLH genes had several cis-elements involved in plant growth and development and abiotic stress responses. In addition, the overexpression of HhbHLH2 increased salt and drought stress tolerance in Arabidopsis.
\end{abstract}

Keywords: bHLH; molecular biology; salt and drought stress

\section{Introduction}

Transcription factors (TFs) are protein molecules with distinct structural and functional characteristics that influence gene expression. In the model plant, Arabidopsis thaliana around $100 \mathrm{TFs}$ have been characterized, and these are crucial for the plant [1]. The basic helix-loop-helix (bHLH) transcription factor family is the second biggest protein family found in plants [2]. It is characterized by a conserved domain consisting of 40-60 amino acids, which consists of two parts: the basic region and the HLH region. The basic region is located at the N-terminus and is composed of 13-17 basic amino acids, which are used as the DNA binding region to identify and specifically bind DNA promoters and target genes. The HLH region is found at the C-terminus of the bHLH domain and consists of two parental helixes bound by relatively distributed (length and primary sequence) loop regions that promote protein interactions [3-5]. An increasing body of evidence indicates that $b H L H$ genes are involved in metabolic regulation, plant growth, and production, and responsiveness to environmental signals in plants. The maize $R$ gene, which is required for anthocyanin production, was the first member of the bHLH family to be identified [6]. Since that time, a growing number of $b H L H$ genes have been found in various plants. A growing amount of evidence suggests that bHLH TFs are important for engagement in plant defense responses, particularly in response to abiotic stress responses such as drought, low temperature, high temperature, and salt stress $[7,8]$. For example, transferring the $\mathrm{M} f b H L H 38$ gene from Myrothamnus flabellifolia to Arabidopsis greatly improved the resistance 
to drought and salt stresses in transgenic plants [9]. Wheat TabHLH49 gene controls the expression of the dehydrin WZY2 gene, improving drought tolerance [10]. Overexpression of the MYC-type $b H L H$ gene ZjICE2 in Zoysia japonica rice resulted in increased chlorophyll content and photosynthesis ability, as well as high cold tolerance [11]. By controlling plant stomata density, stomatal aperture, photosynthesis, and development, the $b H L H$ gene PebHLH35 in Populus euphratica was shown to act as a positive regulator of the drought stress response [12].

The $b H L H$ gene family has been identified in several organisms so far, and has been separated into 15-26 classes in plants based on sequence similarity [13]. In Arabidopsis thaliana, for example, $162 \mathrm{bHLH}$ genes were discovered and divided into 21 subfamilies [14]; $115 \mathrm{bHLH}$ genes, divided into 21 subfamilies, were identified in spine grapes [15]. In red walnut, $102 \mathrm{bHLH}$ genes were discovered, which were split into 15 subfamilies [16]. In pepper, $122 \mathrm{bHLH}$ genes were discovered and split into 21 subfamilies [17]. However, no study on the $b H L H$ gene family has been conducted in Hibiscus hamabo Sieb. et Zucc.

H. hamabo is a shrub plant in the genus Hibiscus, family Malvaceae, and an important semi-mangrove plant [18]. It is commonly used in forests, wetlands, and coastal beaches because of its outstanding salt resistance and fine morphological characteristics [19,20]. At the same time, H. hamabo is also a good material for investigating the mechanism of salt tension in woody plants. Therefore, it is very important to research the H. hamabo $b H L H$ gene family to understand the semi-mangrove plant biological processes in response to stress.

In this study, bioinformatics was utilized to identify members of the bHLH family and to assess their relevant features using genomic sequence and full-length transcriptome datasets. Additionally, we screened for $b H L H$ genes that may be involved in the salt and drought stress biosynthesis pathways in H. hamabo. The study aimed to increase our awareness of the $b H L H$ functions involved in the salt and drought stress responses of H. hamabo, while, our comprehensive research laid the groundwork for additional mechanisms of salt and drought tolerance for $b H L H$ genes in $H$. hamabo, with particular emphasis on identifying potential genes implicated in $H$. hamabo salt and drought stress responses.

\section{Results}

\subsection{Identification and Physicochemical Properties of bHLH Proteins in H. hamabo}

To find $b H L H$ genes in the $H$. hamabo genome, we used a hidden Markov model (HMM) file (PF00010) to conduct a genome-wide HMM-search. There were 167 putative bHLH proteins discovered. The bHLH domains were confirmed by using Pfam online database, and redundant sequences were deleted. Eventually, we obtained 162 sequences from the H. hamabo bHLH family, which we named HhbHLH1-HhbHLH162 based on their chromosomal position. The 162 HhbHLHs gene protein sequences are shown in Table S1. To better characterize these HhbHLHs genes, we examined their physicochemical properties. The $162 \mathrm{HhbHLHs}$ proteins differ in Coding sequence (CDS) length, protein length, molecular weight, and theoretical isoelectric point (pI) (Table S2). Specifically, the CDS lengths ranged from 714 (HhbHLH137) to 2169 (HhbHLH133), while their pIs were between 4.35 (HhbHlH67) and 10.03 (HhbHLH43). Furthermore, the $162 \mathrm{HhbHLH}$ genes were spread at random across 46 chromosomes. The remaining 42 chromosomes, except chromosomes 28, 30, 35, and 46, had varying numbers of HhbHLH genes. Among them, chromosome 24 contained the largest number (10 HhbHLHs) (Table S2).

\subsection{Multiple Sequence Alignment, Phylogenetic Analysis, and Classification of HhbHLH Genes}

Multiple sequence alignment of bHLH domains was used to determine the phylogenetic relationship of HhbHLH proteins, which span across 40-50 amino acids. The bHLH domains of 19 different Arabidopsis bHLH proteins from each of the subgroups were chosen at random for further comparative studies. As shown in Figure 1, the sequences in the bHLH domain were strongly conserved [21], and the sequences of different subgroups were very similar in comparison with Arabidopsis. 


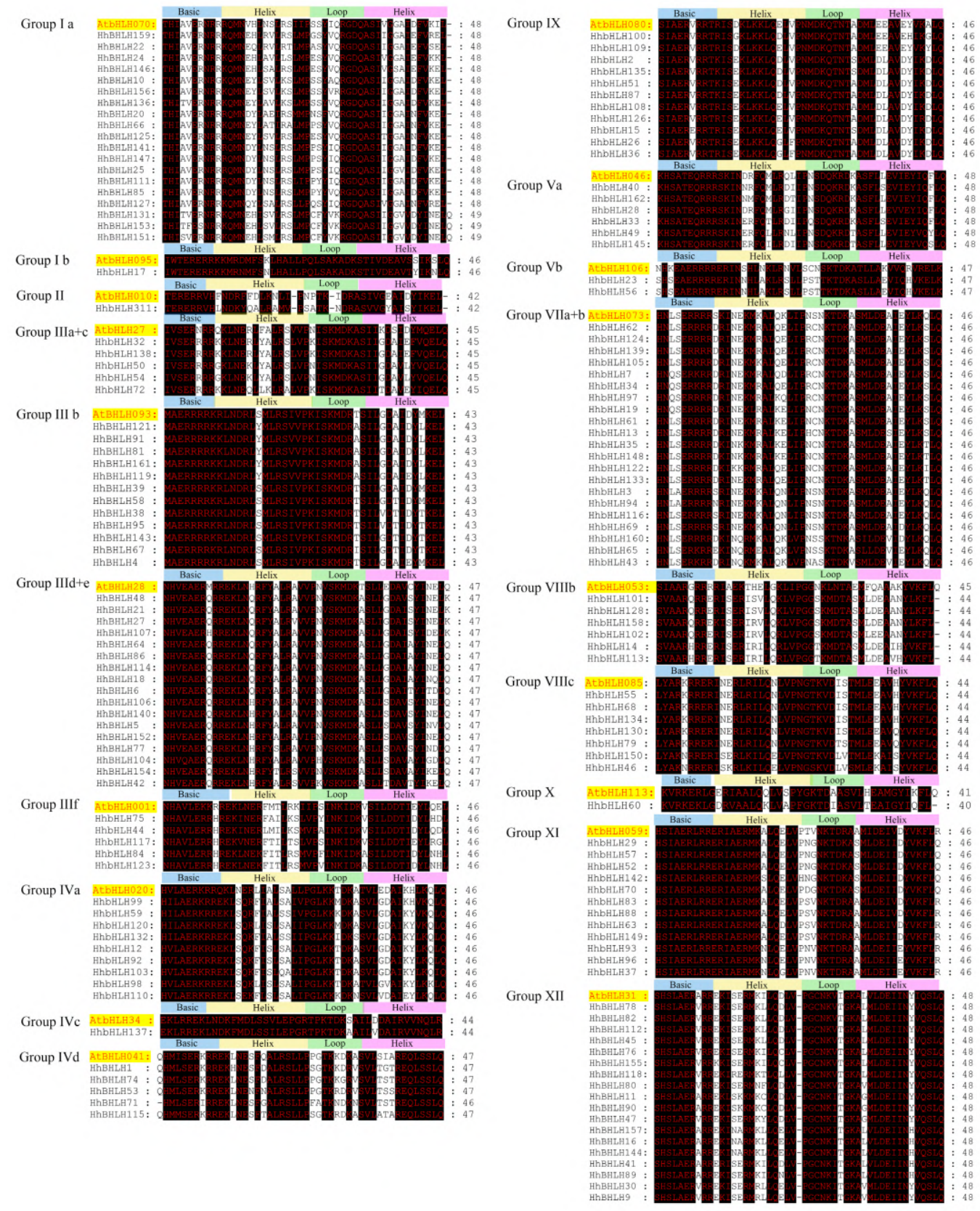

Figure 1. Alignment of the amino acid sequences of multiple HhbHLH and selected Atb HLH domains.

We studied and drew the unrooted phylogenetic tree applying the neighbor-joining (NJ) method based on the similarities between Arabidopsis and H. hamabo bHLH domains. The result revealed that the $162 \mathrm{HhbHLHs}$ gene can be classified into 19 distinct clades. Among them, the VIIa+b subfamily had the most members (20 HhbHLHs), whereas Groups $\mathrm{Ib}$, II, IVc, and X subfamily had the fewest members (one HhbHLH). In addition, the $H$. hamabo bHLH subfamily was extended or contracted to different degrees in comparison with Arabidopsis. The VIIa+b subfamily of Arabidopsis, for example, had 15 members, which grew to 20 in H. hamabo. In subfamilies Ia and Iva, a similar condition existed, while in the $\mathrm{X}$ subfamily there was a substantial reduction in the number of $H$. hamabo genes, from nine to one in Arabidopsis (Figure 2). 


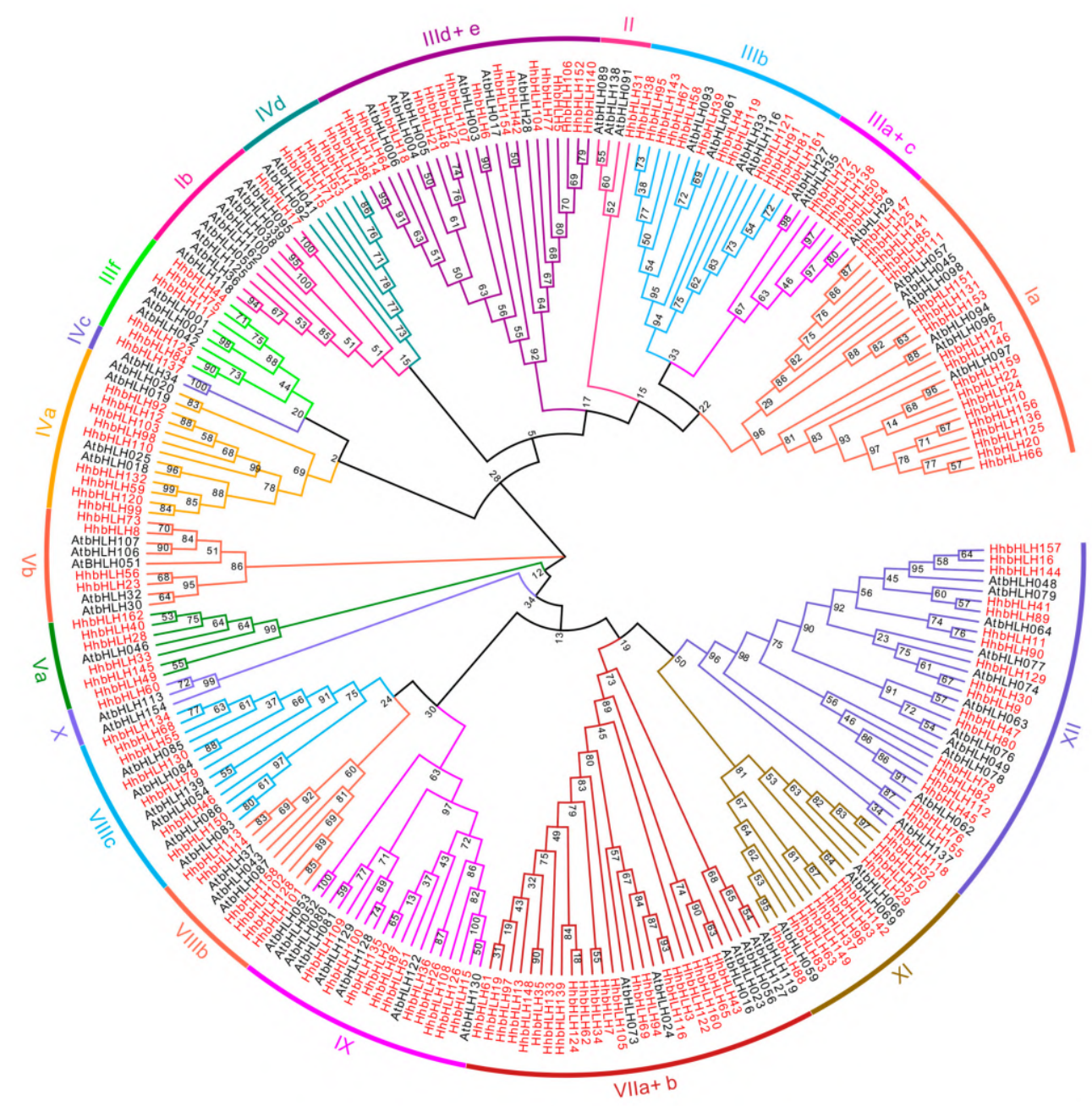

Figure 2. Unrooted phylogenetic tree of bHLH proteins from Arabidopsis thaliana, and H. ham$a b o$. MEGA7 was used to construct the phylogenic tree from the sequences of the domain protein. Evolview was used to annotate and analyze the phylogenic tree. Various background colors show the HhbHLH protein group.

\subsection{Gene Structure and Motif Composition of HhbHLH}

The motif type and composition can determine the function of the protein, and an assessment of its preserved motifs can also be used to determine the evolutionary relationship between the HhbHLH proteins. MEME software was used in this analysis to explore the motif of $162 \mathrm{HhbHLH}$ proteins, yielding a total of 20 motif structures. Other than motifs 1, 4, and 5, which are broadly dispersed bHLH domains, HhbHLH members belonging to the same classes typically share a similar motif composition. (Figure 3b), such as, the XI, XII, and IX subfamilies, which indicates that there may be functional similarities between HhbHLH proteins of the same subfamily. Furthermore, certain motifs are only found in some subgroups, for example, motif 16 occurs only in VIIa+b, and motif 15 appears only in IVd. These conserved motifs may play an important role in specific subgroups, and their specific functions remain to be elucidated. 

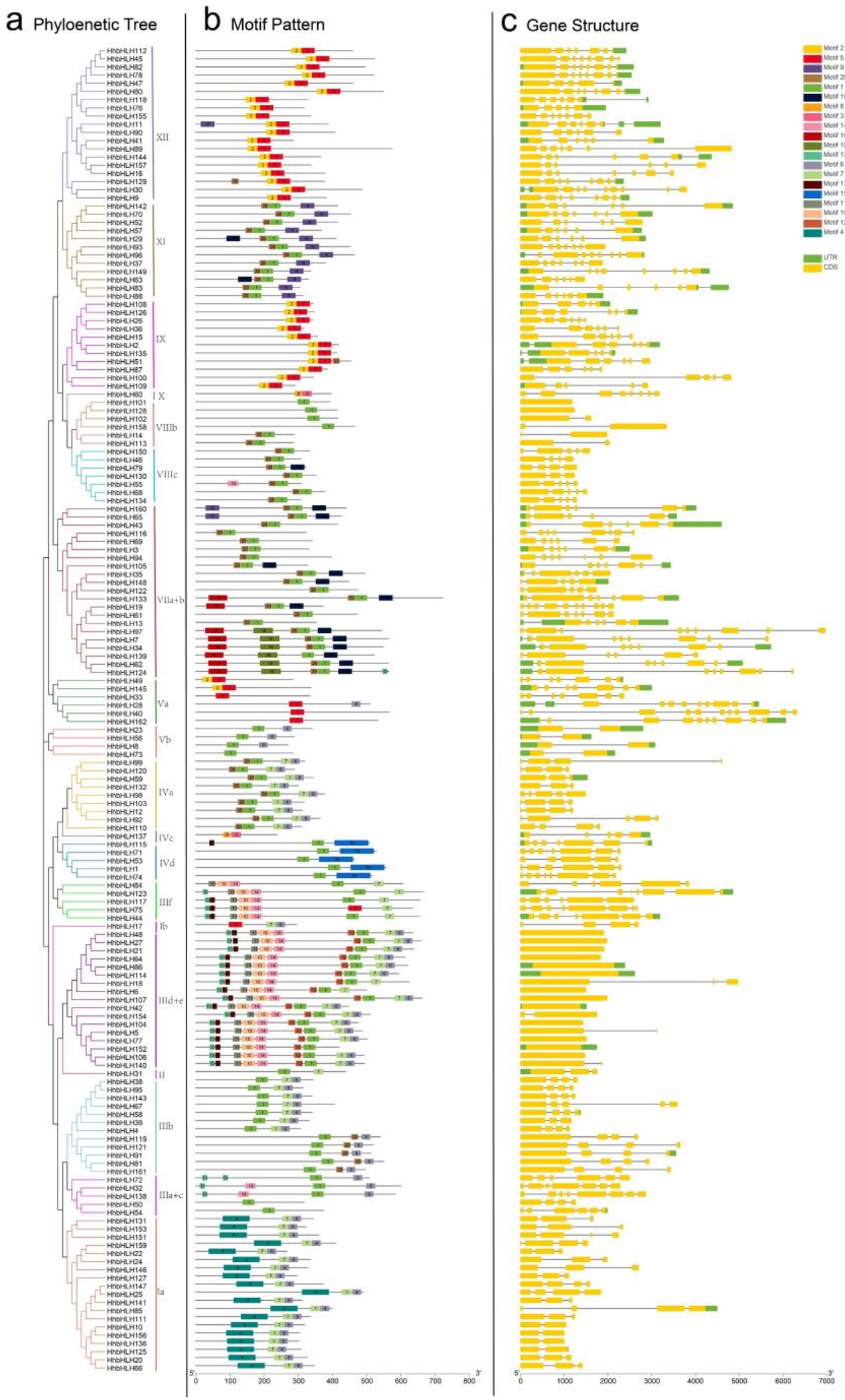

Figure 3. Phylogenetic relationships, gene structure, and architecture of conserved protein motifs in $b H L H$ genes from $H$. hamabo. (a) The phylogenetic tree and the subfamily are shown in different colors. (b) The motif composition of $H$. hamabo bHLH proteins. (c) The exon-intron structure of $H$. hamabo bHLH genes.

We analyzed the structure of all $H h b H L H$ genes, as seen in Figure $3 c$, to gain an understanding of the bHLH family evolution in H. hamabo. Exon numbers ranged from 1 to 
17 in 162 HhbHLH genes. There were no introns in 15 of the genes. These 15 intron genes were divided into two subfamilies, with 13 belonging to the IIId+e subfamily and two to the VIIb subfamily. In addition, the results revealed that the HhbHLHs have not only a large number of exons but also have genetic structure diversity. Exon distribution patterns in the IVd and VIIIc subgroups, for example, are relatively conservative. The number of exons, their distribution, and the length of each exon is all very similar, whereas the exon distribution in the XI and XII subgroups is not. Overall, the phylogenetic study findings, along with the motif compositions and related gene structures of the bHLH members of the subfamily, could support the group classifications reliability.

\subsection{Chromosomal Distribution and Synteny Analysis of HhbHLH Genes}

Gene duplication events, such as whole-genome duplication (WGD)/segmental duplication, tandem duplication, and transposition, are the primary causes of gene family expansion and have a significant effect on the evolution of gene families [22,23]. Through the use of MCScanX software to detect the duplication events of the HhbHLH family, $162 \mathrm{HhbHLH}$ genes were divided into three repetitive events, of which $150(92.59 \%)$ genes were assigned to WGD/segmental events, and $11(0.067 \%)$ genes belonged to the dispersed type. The results indicated that the HhbHLHs gene family expanded primarily as a result of WGD/segmental events. (Table 1 and Table S3).

Table 1. Numbers of $b H L H$ genes from different origins in H. hamabo.

\begin{tabular}{|c|c|c|c|c|c|}
\hline Duplication Type & Singleton & Dispersed & Proximal & Tandem & WGD/Segmental \\
\hline $\begin{array}{l}\text { No. of } b H L H \text { genes from } \\
\text { different origins } \\
\text { (percentage) }\end{array}$ & $0(0.00 \%)$ & $11(6.79 \%)$ & $1(1.62 \%)$ & $0(0.00 \%)$ & $150(92.59 \%)$ \\
\hline
\end{tabular}

To better understand the evolutionary process of the HhbHLH genes, we used intragenomic synteny analysis to identify conserved chromosome blocks within H. hamabo. We mapped $162 \mathrm{HhbHLH}$ genes on 46 chromosomes using annotation information of the genome-wide data. Except for chromosomes 28, 30, 35, and 46, the remaining 42 chromosomes had different numbers of HhbHLH gene distributions, of which chromosome 24 contained the most $(10 \mathrm{HhbHLHs})$. Furthermore, there was no positive relationship between the number of genes on a chromosome and its length (Figure 4). We used intragenomic synteny analysis to investigate the evolutionary mechanism behind the $\mathrm{HhbHLH}$ gene and discovered that there are a total of 68 pairs of $H h b H L H$ genes that had a collinearity relationship (Figure 4). The Ks value can be used to estimate the evolutionary date of WGD/segmental duplication events (synonymous substitutions per site) [24]. According to the magnitude of the Ks value, we found that the HhbHLH gene family WGD/segmental events occurred in different periods; some occurred in a distant period (Ks $>1)$ and others occurred in a relatively recent period $(\mathrm{Ks}<0)($ Table $\mathrm{S} 4)$. The $\mathrm{Ka} / \mathrm{Ks}$ ratio can be used to represent the selection intensity and direction. A Ka/Ks value of one indicates neutral evolution, a $\mathrm{Ka} / \mathrm{Ks}$ value greater than one indicates positive selection, and a $\mathrm{Ka} / \mathrm{Ks}$ value less than one indicates purifying selection [25]. The Ka/Ks ratio of all homologous HhbHLH genes was less than one in the HhbHLH gene family. This result suggests that HhbHLHs evolved primarily under purifying selection (Table S4). 


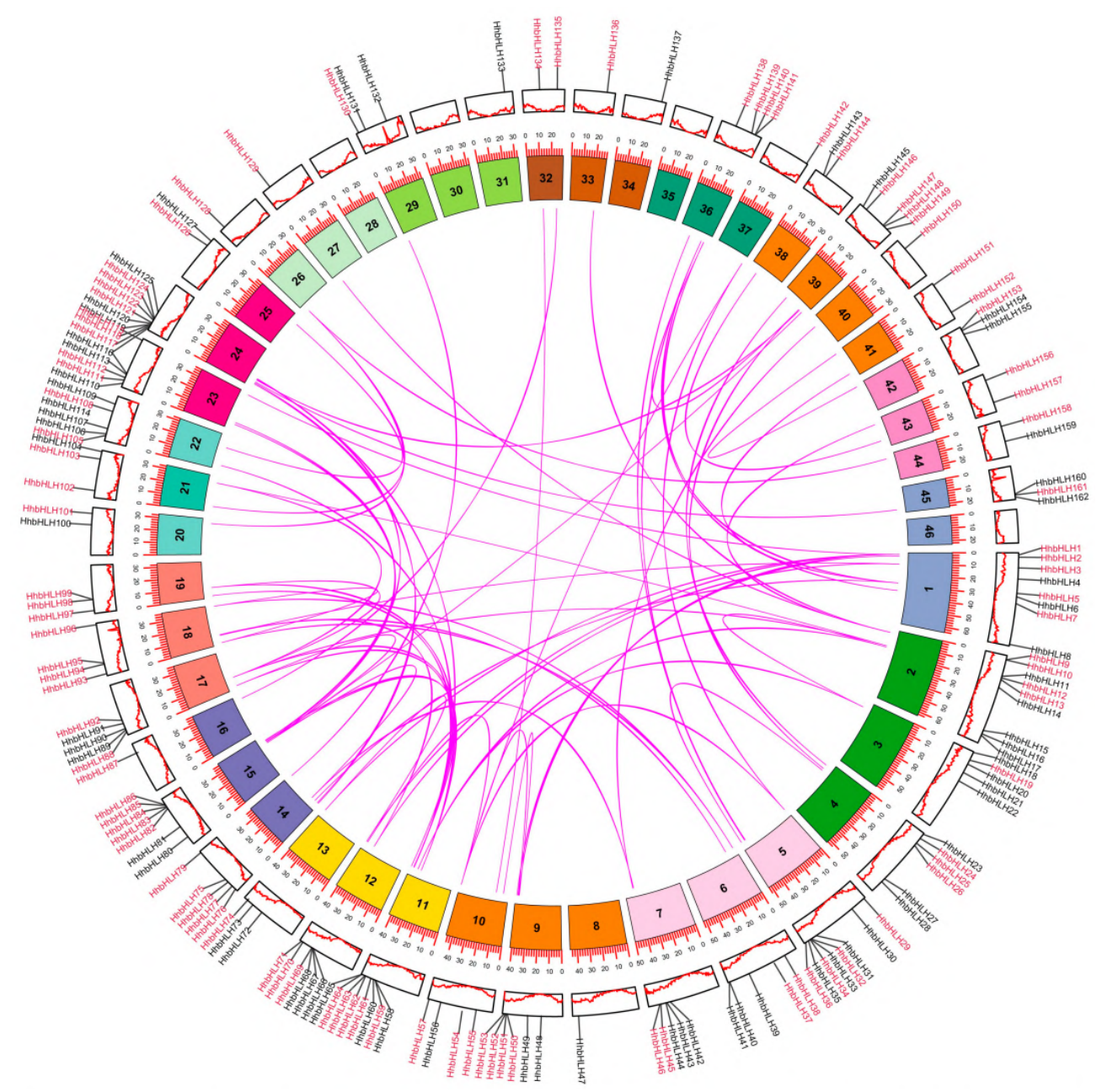

Figure 4. Distribution and collinearity of the HhbHLHs. Black lines along the circumference of the circle mark the positions of genes on chromosomes. The lines inside the circle indicate collinearity relationships among $H h b H L H$ genes.

We created comparative syntenic maps between H. hamabo and Arabidopsis and Populus to get a better grasp of the phylogenetic mechanisms underlying the H. hamabo bHLH family. In total $60 \mathrm{HhbHLH}$ genes showed a syntenic relationship with those in Arabidopsis, and $26 \mathrm{HhbHLH}$ genes showed a syntenic relationship with those in Populus (Figure 5). Some of the HhbHLH genes, such as HhbHLH11 and HhbHLH141, were related to at least three syntenic gene pairs (especially in Arabidopsis). Additionally, several bHLH collinear gene pairs identified between $H$. hamabo and Arabidopsis were linked to highly conserved syntenic blocks spanning over 100 genes. This phenomenon suggested that an evolutionary relationship may exist between the bHLH gene family of H. hamabo and that of Arabidopsis.

\subsection{Promoter Analysis of HhbHLH}

In this study, 162 cis-acting elements in the upstream 2000 bp sequence of the HhbHLH gene were analyzed and, finally, a mass of potential cis-elements was obtained (Table S5). The visualization of nine cis-acting elements that are more important in stress response is shown in Figure 6. The results show that genes responsive to light, low temperature, gibberellin, MeJA, drought stress, wounds, and MYB binding sites involved in drought and other elements related to stress response were abundantly enriched in the promoter region of the HhbHLH gene. This result indicates that the $H h b H L H$ gene may be involved in a variety of abiotic stress response and defense mechanisms. 

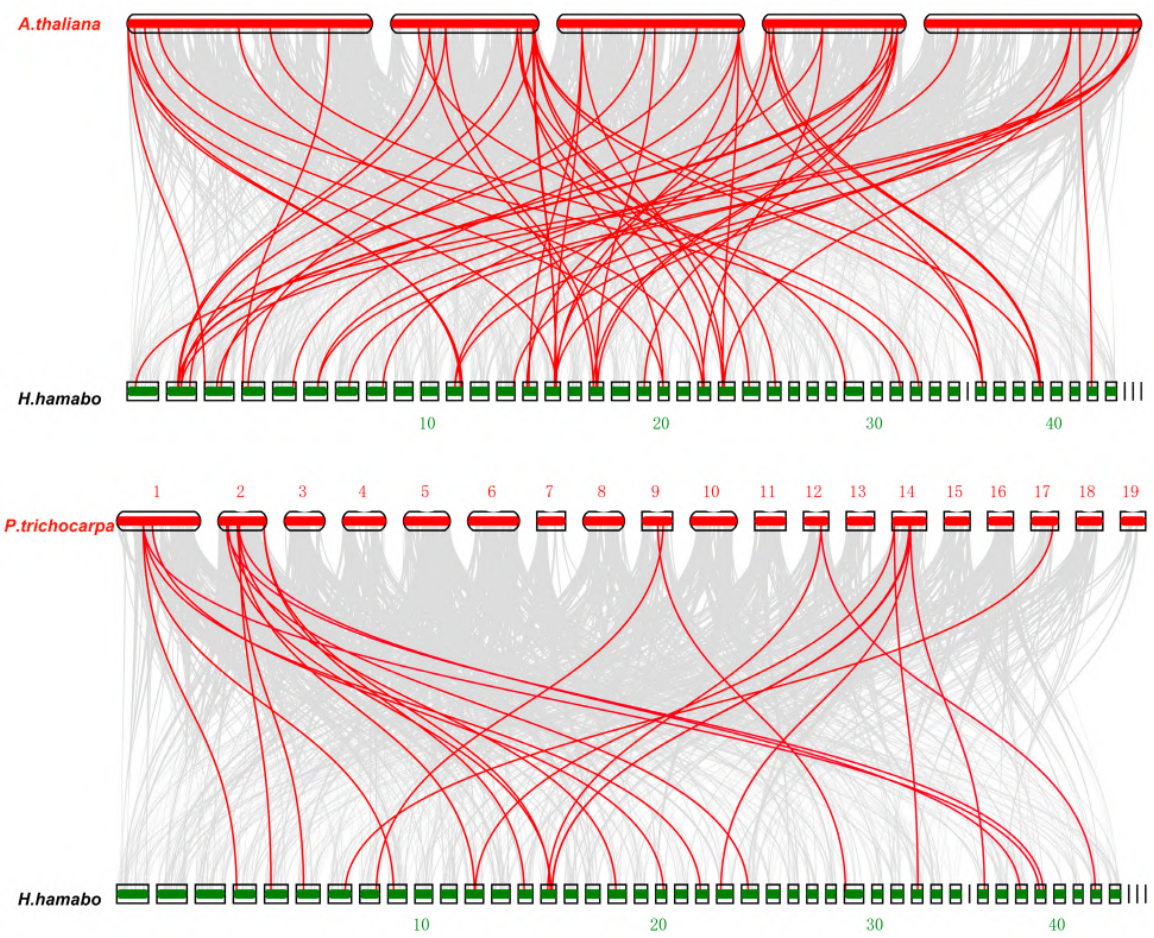

Figure 5. Synteny analysis maps of H. hamabo with Arabidopsis and Populus. Gray lines in the background indicate the collinear blocks within H. hamabo and other plant genomes, while the red lines highlight the syntenic $b H L H$ gene pairs.
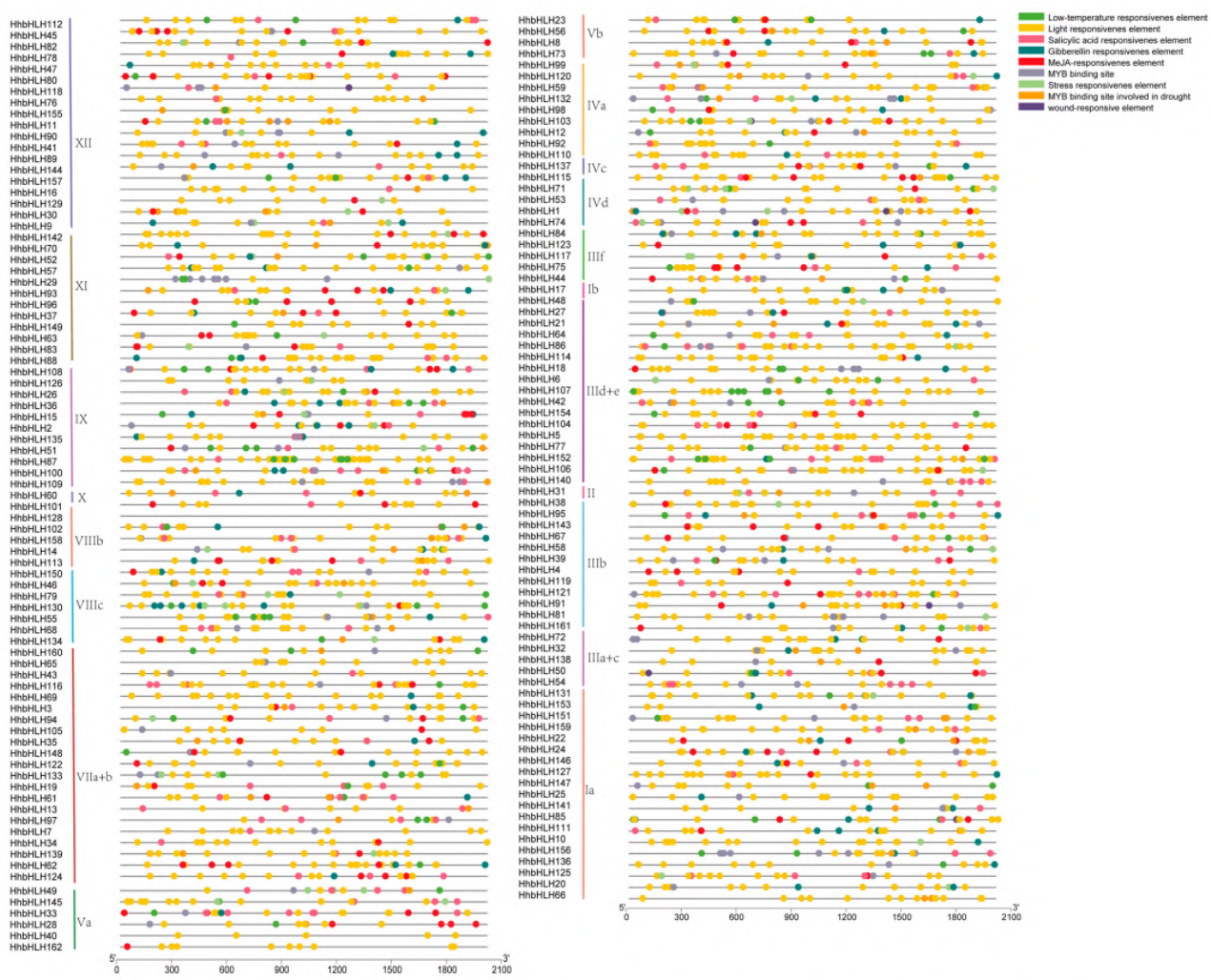

Figure 6. Analysis of the promoters of $162 \mathrm{bHLH}$ genes in H. hamabo using cis-element analysis. Different hues denoted substances associated with plant hormones (salicylic acid, gibberellin, and methyl jasmonate) and stress resiliency (light, low temperature, wound-responsive, and drought inducibility). 


\subsection{Expression Profile and Patterns of HhbHLH Genes in Response to Drought and Salt Stresses}

We examined the expression patterns of $162 \mathrm{HhbHLH}$ genes using transcriptome data from $H$. hamabo leaves under drought (15\% PEG6000) and salt (400 $\mathrm{mM} \mathrm{NaCl}$ ) stress conditions in this study. Of the $162 \mathrm{HhbHLH}$ genes, ten genes were not expressed in the transcriptome data, while the remaining genes were expressed (FPKM $>0$ ) (Table S5). The expression of some genes showed the same trend under the two stresses. For example, the HhbHLH2 of subfamily XI, HhbHLH21 and HhbHLH48 of subfamily IIId+e, HhbHLH31 of subfamily II, and HhbHLH35 genes of VIIa+b were up-regulated under both stresses. HhbHLH31 from subfamily II, HhbHLH75 from subfamily IIIf, and HhbHLH78 from subfamily XII were all down-regulated under both stresses. The results suggest that these genes may play a critical role in $H$. hamabo response to drought and salt stress. Some genes have different expression patterns under the two stresses. For example, HhbHLH2O of subfamily Ia, HhbHLH30 of subfamily XII, and HhbHLH67 of subfamily III by are significantly up-regulated under drought stress and down-regulated under salt stress, while the XI c subfamily, HhbHLH83, and HhbHLH29, were significantly up-regulated under salt stress and down-regulated under drought stress, indicating that these genes may have different regulatory modes in $H$. hamabo under drought and salt stresses. Furthermore, under both stresses, the genes of subfamily VIIIb and VIIIc had lower expression levels, implying that the involvement of these two subfamilies in the H. hamabo reaction to drought and salt stresses may not be apparent (Figure 7a).

We chose $15 \mathrm{HhbHLH}$ genes at random to study their function further by quantitative real-time PCR (RT-qPCR). The expression trends of these genes under $\mathrm{NaCl}$ and PEG treatment for $0 \mathrm{~h}, 6 \mathrm{~h}$, and $24 \mathrm{~h}$ were shown to be largely compatible with the transcriptome data, demonstrating the reliability of the transcriptome data. At the same time, three time points $(1 \mathrm{~h}, 2 \mathrm{~h}, 12 \mathrm{~h}$ ) were added to the analysis of the expression profiles of the genes under drought and salt stresses to further understand the changes of gene expression level in different treatment periods of stress. Compared with the transcriptome data, the expression trend of some genes was more abundant after the new time point was added. For example, HhbHLH51, HhbHLH78, HhbHLH82, and HhbHLH84 showed a significant upregulation after $1 \mathrm{~h}$ of drought stress and were then significantly down-regulated. A similar expression was observed in HhbHLH57, HhbHLH78, HhbHLH136, and HhbHLH78 under salt stress. This phenomenon indicates that these genes may play different roles in different periods of stress. At the same time, some genes, such as HhbHLH2O and HhbHLH26, were significantly up-regulated during drought and salt stresses after $12 \mathrm{~h}$, while there was no obvious differential expression in other periods. In addition, some genes have different expression trends under drought and salt stress. For example, HhbHLH8 is up-regulated after $1 \mathrm{~h}$ of drought stress, but down-regulated after $1 \mathrm{~h}$ of salt stress. HhbHLH2O is upregulated after $12 \mathrm{~h}$ of drought stress and down-regulated after $12 \mathrm{~h}$ of salt stress. These results show that under different treatment times, some genes may respond to the two stresses through different regulatory ways. In conclusion, the results of RT-qPCR effectively supplement the transcriptome data and provide a reference for the future exploration of the function of the genes (Figure $7 \mathrm{~b}, \mathrm{c}$ ). 


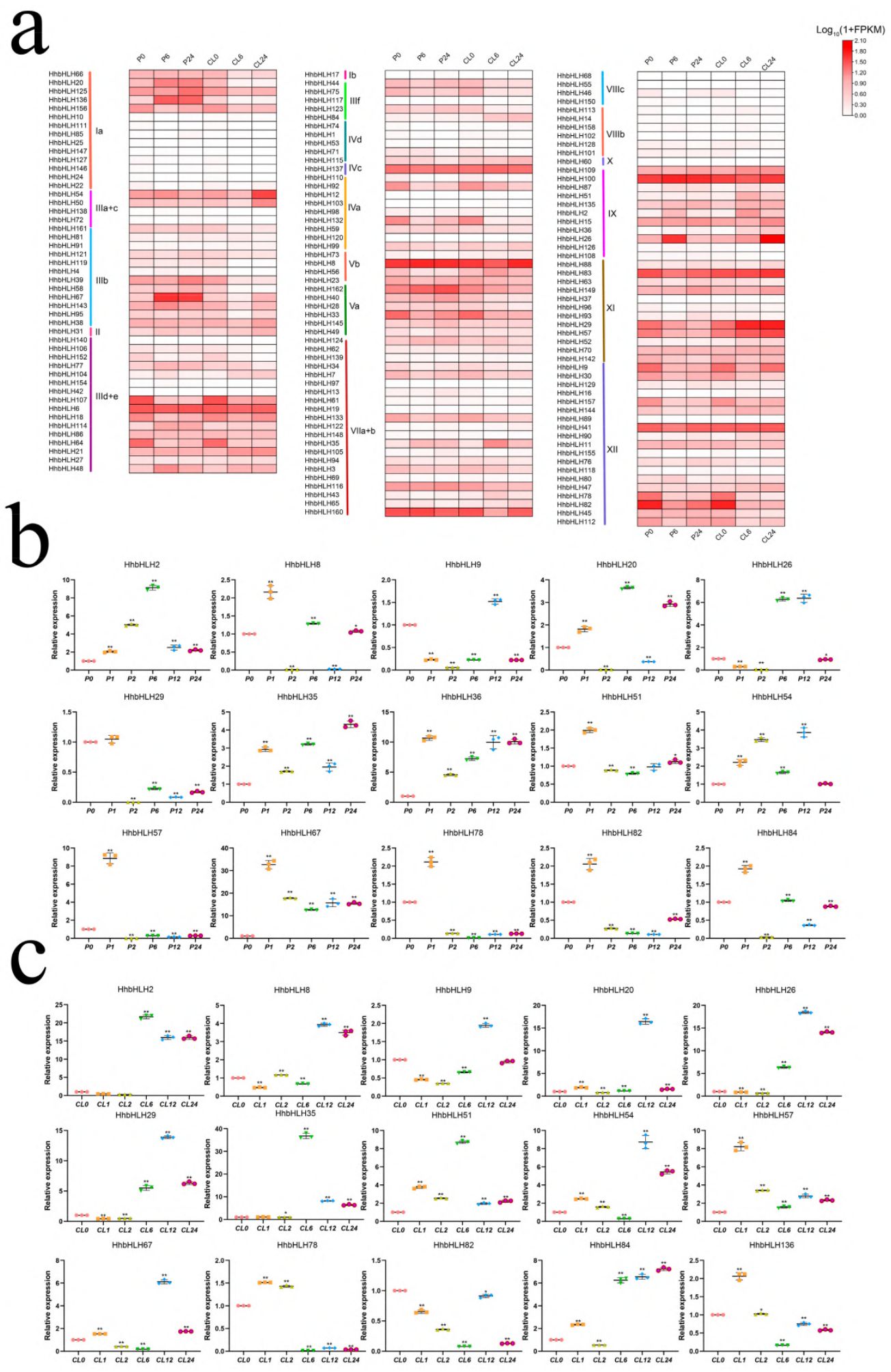

Figure 7. Expression profile of $H h b H L H s$ under drought and salt stresses. (a) A heatmap shows the expression level of $162 \mathrm{HhbHLH}$ genes with different subfamilies in salt and drought stress of $H$. hamabo. Expression differences are observed in different colors. The P0, P6, P24 represent 0 h,6 h, and 24 h were treated with PEG; CL0, CL6, and CL24 represent 0 h, 6 h, and $24 \mathrm{~h}$ were treated with $\mathrm{NaCl}$. A color change indicates a change in expression level; white indicates a lower level of expression, whereas red indicates a higher level of expression. (b) Relative expression of 15 HhbHLH genes chose at random with PEG treatment, P0, P1, P6, P12, and P24 represent 0 h, 1 h, 2 h, 6 h, 12 h, and 24 h were treated with PEG. (c) Relative expression of $15 \mathrm{HhbHLH}$ genes chosen at random with $\mathrm{NaCl}$ treatment, CL0, CL1, CL6, CL12, and CL24 represent $0 \mathrm{~h}, 1 \mathrm{~h}$, $2 \mathrm{~h}, 6 \mathrm{~h}, 12 \mathrm{~h}$ and $24 \mathrm{~h}$ were treated with $\mathrm{NaCl}$. The $A C T$ gene was used to normalize the data, and vertical bars represent standard deviation. Asterisks denote genes that are significantly up-or down-regulated in comparison to the untreated control (* $p<0.05,{ }^{* *} p<0.01$, Student's $t$-test). 


\subsection{Expression Patterns of HhbHLH Genes in Response to Different Treatments}

To further understand whether the above 15 HhbHLH members would be affected by other abiotic stresses and hormone treatments, we used RT-qPCR to analyze their expression patterns under low temperature, high temperature, abscisic acid (ABA), and salicylic acid (SA) treatments. In general, some genes with higher expression levels under drought and salt stresses showed similar expression patterns under abiotic and hormonal stress. For example, HhbHLH2, HhbHLH8, and HhbHLH26 had similar expression patterns under the four stresses. Both had a significant trend in up-regulation. This result is similar to their expression under drought and salt stresses, indicating that these genes may play a very important role in the response of $H$. hamabo to stress. Some HhbHLH genes can be significantly induced or inhibited by a variety of treatments. For example, HhbHLH2 and HhbHLH82 have a significant response to low temperature, high temperature, ABA, and SA treatments. One treatment can also induce the expression of multiple $\mathrm{HhbHLH}$ genes at the same time. For example, cold treatment simultaneously induces the expression of HhbHLH2/20/26/29/57/84 and other genes. In addition, some genes had the opposite expression patterns under different treatments. For example, HhbHLH2O is significantly upregulated under SA stress but exhibits a significant down-regulation under ABA stress. This phenomenon indicates that $H h b H L H$ family genes can participate in multiple conditions, and their regulation is different under different stresses (Figure 8).
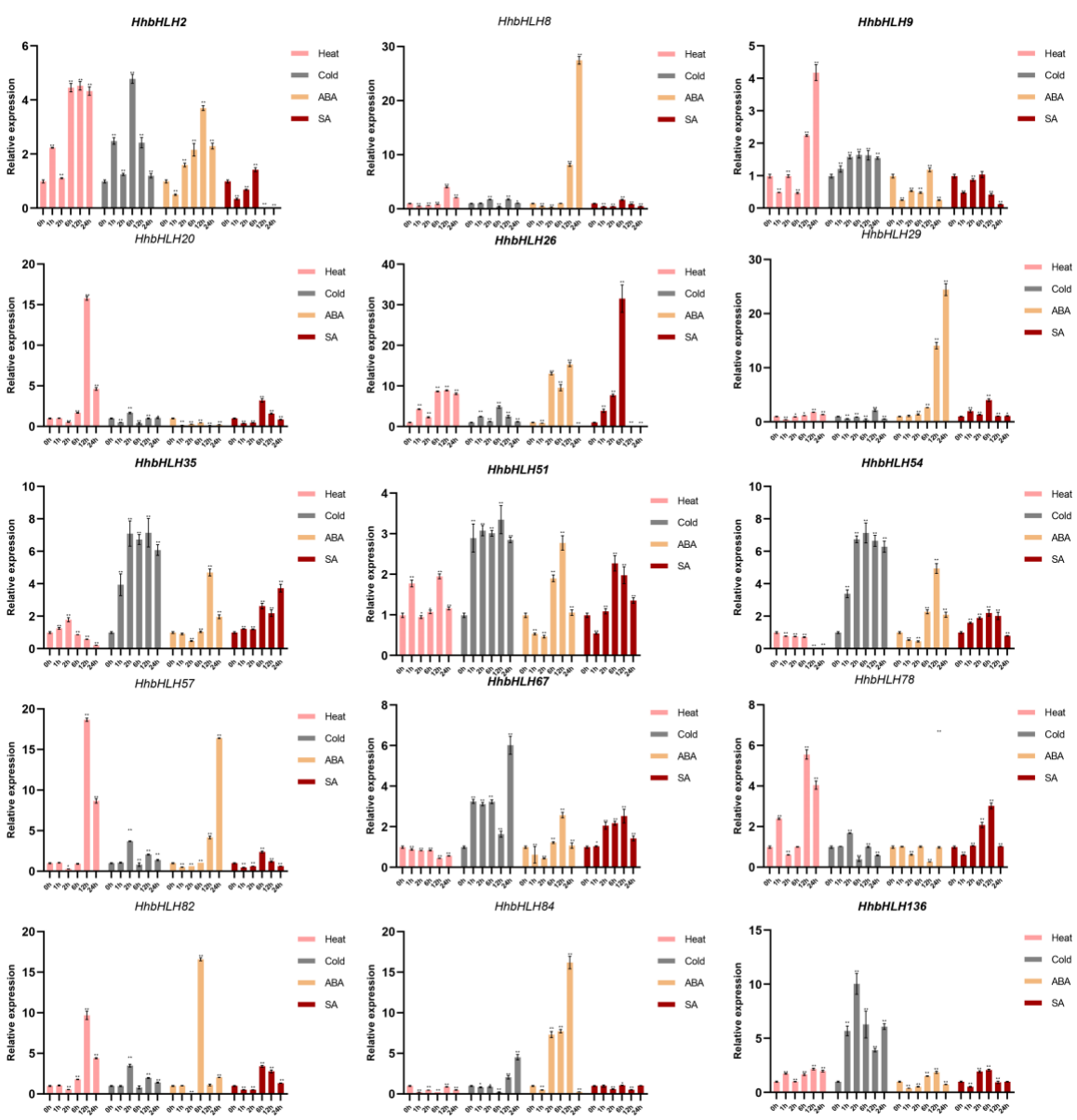

Figure 8. Expression profiles of 15 selected $H h b H L H$ genes in response to various stress treatments. Different colors represent different stress treatments. Pink represents heat stress, gray represents cold stress, yellow represents ABA stress, and red represents SA stress. Asterisks denote genes that are significantly up- or down-regulated in comparison to the untreated control $\left({ }^{*} p<0.05,{ }^{* *} p<0.01\right.$, Student's $t$-test). 


\subsection{Overexpression of HhbHLH2 Increased Salt and Drought Stress Tolerance in Arabidopsis}

Previous research has shown that the bHLH122 gene in Arabidopsis can be expressed in significant amounts under drought stress and that plants with the AtbHLH122 gene overexpressed are more drought tolerant than wild plants [26]. The HhbHLH2 gene, which belongs to subfamily IX, showed higher expression levels in drought and salt stresses in $H$. hamabo leaves. This result prompted us to further explore its potential functions under drought and salt stresses. To study the function of the HhbHLH2 gene, which is driven by CaMV 35S promoter this was transferred into Arabidopsis (Col-0) via Agrobacteriummediated transformation, and homozygous T3 generation plants (OE-3, OE-5, and OE-6) were obtained through screening. Under normal conditions, there was no obvious growth difference between wild-type and transgenic Arabidopsis (Figure 9a,b). As the $\mathrm{NaCl}$ and D-mannitol(D-M) concentration continued to increase, although the root length of WT and transgenic plants decreased consistently, the decline in transgenic plants was slower than that in WT plants. Under $50 \mathrm{mM} \mathrm{NaCl}$, the root length of WT plants was reduced by $57.98 \%$, while the root length of transgenic plants was reduced by $11.64 \%-53.54 \%$. The average root length of the transgenic plants was 1.72-fold that of the WT (Figure 9c,d). Under $200 \mathrm{mM}$ D$\mathrm{M}$, the root length of WT plants was reduced by $80.88 \%$, while the root length of transgenic plants was reduced by $2.28-12.00 \%$. The average root length of the transgenic plants was 5.02-fold that of the WT (Figure 9e,f). Overall, these results indicate that HhbHLH2 can participate in the regulation of drought and salt stress responses, while overexpression of HhbHLH2 can endow transgenic plants with drought and salt stress tolerance.
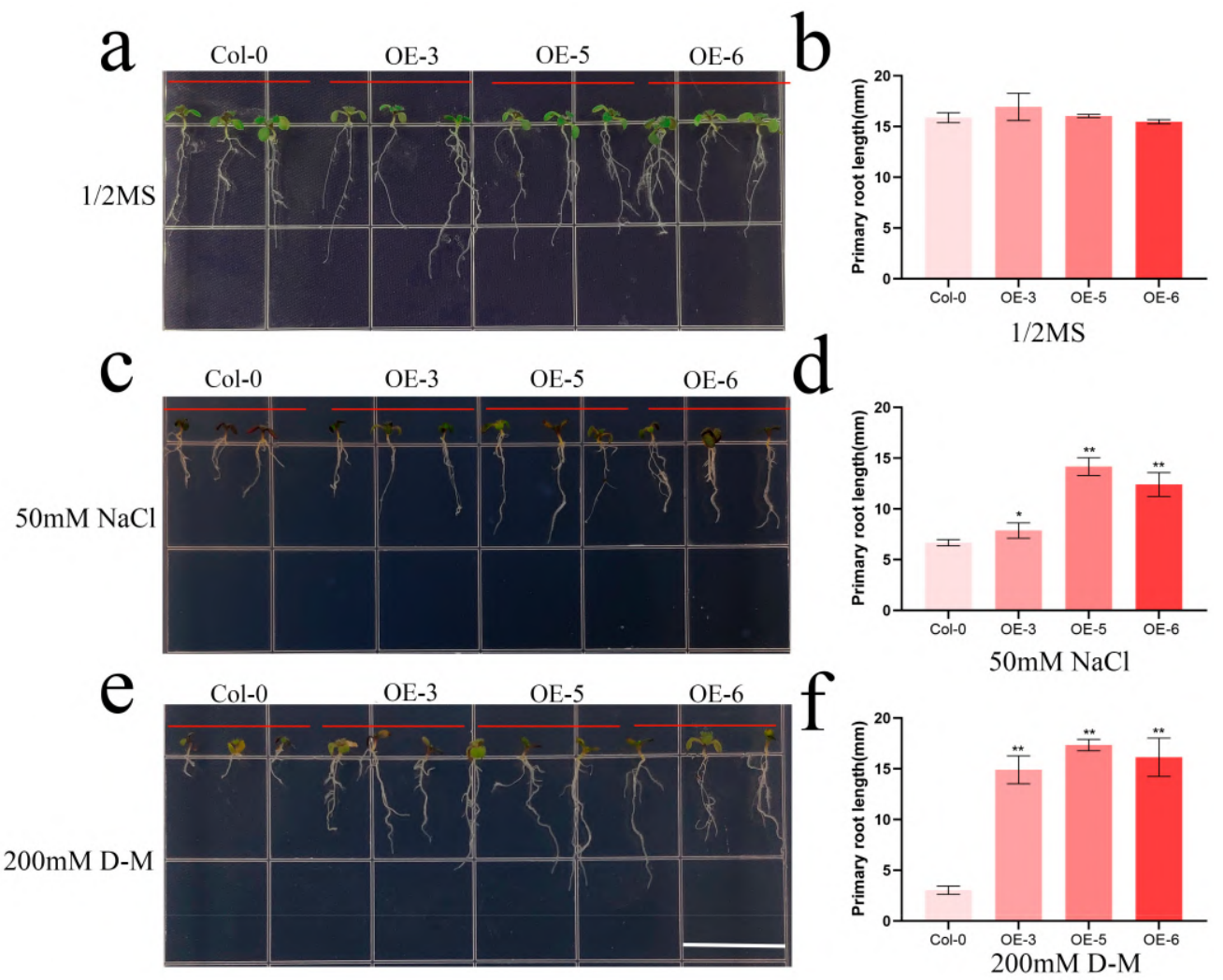

Figure 9. Effects of salt and drought stress on root length of wild-type (col-0) and Arabidopsis overexpressing HhbHLH2 (OE-3, OE-5, and OE-6). (a) Three-day-old seedlings were transferred to MS medium for 7 days. (b) Root length statistics in MS medium. (c) Three-day-old seedlings were transferred to MS medium in $50 \mathrm{mM} \mathrm{NaCl}$ for seven days. (d) Root length statistics in $50 \mathrm{mM}$ $\mathrm{NaCl}$ for seven days. (e) Three-day-old seedlings were transferred to MS medium in $200 \mathrm{mM} \mathrm{D-M}$ for 7 days. (f) Root length statistics in MS medium $200 \mathrm{mM}$ D-M for 7 days. Asterisks indicate the corresponding gene significantly up- or down-regulated compared with the untreated control (* $p<0.05,{ }^{* *} p<0.01$, Student's $t$-test). 


\section{Discussion}

The bHLH protein family is one of the largest TF families in plants and can participate in many pathways such as plant growth and metabolism. The current $b H L H$ gene family genome-wide identification work has been completed in multiple species, such as $162 \mathrm{bHLH}$ genes in Arabidopsis thaliana [14], 192 bHLH genes in tobacco [27], 197 bHLH genes in pear [7]. We identified $162 \mathrm{HhbHLH}$ genes in this study using data from the H. hamabo genome. Based on their chromosomal location, these genes were named HhbHLH1-HhbHLH162. The conserved domains of the $H$. hamabo bHLH protein were evaluated by multiple sequence alignment. According to the conserved domains, the $162 \mathrm{HhbHLH}$ proteins could be divided into 19 subgroups. The specific number of subgroup classifications of the current plant bHLH family does not have a unified standard but is usually considered to be between 15-32 subgroups $[7,14,28]$. The number of genes in the different subgroups of the H. hamabo bHLH family varies from 1 to 20. Compared with Arabidopsis, the $b H L H$ genes in $H$. hamabo are different among the subgroups, such as VIIa+b, Ia, and IVa, by the degree of expansion or contraction.

The type and composition of motifs can determine the function of the protein, and the evolutionary relationship between HhbHLH proteins can also be determined by analyzing their conservative motifs. In this study, the online MEME program was used to analyze the motifs of $162 \mathrm{HhbHLH}$ proteins, and a total of 20 motif structures were obtained. The composition patterns of these motifs are almost the same as the results of phylogenetic analysis, the composition is similar in the same subfamily. At the same time, we analyzed the structure of all HhbHLH genes and found that $b H L H$ members in the same group had similar gene structures. These findings further established the validity of the HhbHLHs classification.

Gene duplication events are very common in the evolution of plants, and they frequently play a critical role in the growth of gene families [29]. The $162 \mathrm{HhbHLH}$ genes were divided into three types of repetitive events, of which 150 (92.59\%) genes were assigned to WGD/segmental events, and $11(0.067 \%)$ genes belonged to the dispersed type, which indicates that WGD/segmental events occur in H. hamabo. In addition, with synteny analysis, it was found that 60 and $26 \mathrm{HhbHLH}$ genes have a syntenic relationship with Arabidopsis and poplar bHLH families, respectively. Some of the HhbHLH genes are connected to at least three syntenic gene pairs (especially in Arabidopsis thaliana), such as HhbHLH11 and $H h b H L H 141$, these genes may have played a key role in the $b H L H$ gene family.

Substantial evidence proved that the $b H L H$ gene family plays a critical role in plants, especially in plant response to drought and salt stress. For example, overexpression of the MdSAT1 gene in apples increases the resistance of apple callus and transgenic Arabidopsis to drought and salt stresses [30], and the CsbHLH041 gene in cucumber enhances the tolerance of transgenic cucumber seedlings to salt and ABA [15]. In this study, we analyzed the transcriptome data of $H$. hamabo under drought and salt stresses and revealed the expression pattern of the HhbHLH genes under these stresses. Except for a few genes, the results indicated that the expression of the majority of $H h b H L H s$ changed significantly. After that, 15 highly expressed genes under drought and salt stress were screened and further analyzed by RT-qPCR. The results showed that the gene expression was consistent with the transcriptome data at the same time, which proved the reliability of the transcriptome data. In addition, three time points $(1 \mathrm{~h}, 2 \mathrm{~h}, 12 \mathrm{~h})$ were added to the analysis of the expression profiles of these genes under drought and salt stress. These results effectively supplemented the transcriptome data and provided a basis for the exploration of functional genes in the future. After that, we analyzed the expression of these 15 genes under heat, cold, ABA, and SA treatment, and screened a $H h b H L H 2$ gene with significant differences under various stresses for further study. Previous studies have found that the Arabidopsis IX subfamily AtbHLH122 gene can be expressed in large quantities under drought stress, and compared with wild plants, the plants with the AtbHLH122 gene overexpressed have stronger tolerance to drought stress [26]. In this study, the overexpression of Arabidopsis thaliana confirmed that HhbhLh2 can improve the drought and salt stress tolerance of 
transgenic plants. In conclusion, the present study represents the first analysis of the $b H L H$ gene family of the semi-mangrove plant $H$. hamabo, and the isolated identification of these transcription factors may help elucidate the molecular genetic basis of $H$. hamabo in response to drought and salt stress as well as reveal the importance of $b H L H$ genes in response to abiotic stress.

In conclusion, this is the first comprehensive and systematic analysis of bHLH transcription factors in the semi-mangrove plant H. hamabo, and isolation and identification of these transcription factors help clarify the molecular genetic basis of $H$. Hamabo response to drought and salt stress and reveal the importance of $b H L H$ genes in response to abiotic stress. The expression analysis of $H h b H L H s$ genes also lays a strong foundation for future studies on the regulatory functions of bHLH proteins during abiotic stress response in $H$. Hamabo and will be able to further help understand this gene family in other plants. In addition, the functional identification of the $\mathrm{HhbHLH} 2$ gene also provides a basis for further study on the regulatory network of H. Hamabo in response to drought and salt stress in the future.

In conclusion, the results of this study reveal the importance of the $b H L H$ gene in response to abiotic stress. This work may help to clarify the functions of $b H L H$ family genes in protein interaction, signal pathway regulation, and defense response under different stress conditions, and provide basic resources for the future study of semi-mangrove plant tolerance to drought and salt stress.

\section{Materials and Methods}

\subsection{Gene Identification}

The Pfam protein family database was queried for the HMM file corresponding to the bHLH domain (PF00010) (http:/ / pfam.sanger.ac.uk/, accessed on 16 March 2021) [31]. The HMMER (v. 3.1) software was used to search for the $b H L H$ gene in the H. hamabo genome database using default parameters and a cutoff value of 0.001 [32]. Some genes do not contain the bHLH domain and have no obvious structural features to be deleted artificially. The genome gene ID corresponding to HhbHLH is shown in Table S4. The sequence length, molecular weight, and pI values for the bHLH protein were determined using the ExPasy website tools (http:/ / web.expasy.org/protparam/, accessed on 16 March 2021).

\subsection{Sequence Analysis}

The default parameters of ClustalW (v. 2.1, C ++, USA) were used to align the protein sequence of the bHLH domain of the HhbHLH protein, and then GeneDoc (www.psc. edu/biomed/genedoc, accessed on 16 March 2021) software was used to manually adjust the amino acid sequence in the bHLH domain. MEME SUITE (v. 4.12.0, JAVA, Australia) software was used to analyze the conserved motifs in the HhbHLH protein. The following parameters were used: any number of repetitions; the maximum number was twenty, and the optimal width was between six and one hundred residues [33]. The HhbHLH gene structure was determined through the program GSDS (http://gsds.cbi.pku.edu.cn, accessed on 16 March 2021) [34]. Tbtools (v. 1.089, JAVA, China) were used to visualize the results [35].

\subsection{Phylogenetic Analysis and Classification}

According to the classification of AtbHLH in Arabidopsis and the comparison of the bHLH conserved domains of HhbHLH and AtbHLH proteins, the identified HhbHLHs were divided into different subgroups. The bHLH proteins of Arabidopsis were downloaded from the TAIR (https: / / www.arabidopsis.org/, accessed on 16 March 2021) A phylogenetic tree was constructed using the NJ method in MEGA 7.0 [36].

\subsection{Chromosomal Distribution and Gene Duplication}

The GFF file was used to extract the HhbHLH gene's chromosome location information. The same procedure was used to analyze the synteny among the HhbHLHs in 
PGDD (http:/ / chibba.agtec.uga.edu/duplication/, accessed on 16 March 2021). Primarily, local all-vs-all BLASTP searches were performed on identified HhbHLH genes. Following that, using the BLASTP result and gene location information as input files, MCScanX was used to determine syntenic gene pairs [37]. We used the MCScanX package downstream analysis tool (duplicate gene classifier) to identify tandem, proximal dispersed, and segmental/whole-genome duplications (WGD) of HhbHLH family genes. We analyzed the $\mathrm{Ka}$ and Ks values using the KaKs Calculator 2.0 [38]. To estimate the dates of segmental duplication events, the mean Ks was calculated for succeeding pairs of homologous genes within $100 \mathrm{~Kb}$ on all sides of the HhbHLH genes. Tbtools (v. 1.089, JAVA, China) were used to visualize the results.

\subsection{Plant Materials and Treatments}

H. hamabo seeds were collected from Nanjing's Sun Yat-Sen Memorial Botanical Garden. The seeds were soaked in concentrated sulfuric acid for $10 \mathrm{~min}$ and then cultured in a greenhouse under aseptic conditions for 3 weeks $(16 \mathrm{~h} / 8 \mathrm{~h}$ light/dark; relative humidity $65 \%)$. Then, the seedlings with the same taproot length were transferred to a $50 \mathrm{~mL}$ centrifuge tube and cultured in half-strength Murashige and Skoog (1/2 MS) nutrient solution at $\mathrm{pH} 5.8$ for 1 week before treatment. The seedlings were renewed every 2 days during the growth period. For drought or salt stress treatments, the two groups of seedlings were placed in 1/2 MS solution containing either 15\% PEG6000 or $400 \mathrm{mM} \mathrm{NaCl}$. For hormone treatment, $H$. hamabo seedlings were treated with $200 \mu \mathrm{M}$ SA and $400 \mu \mathrm{M}$ ABA. Plants were exposed to $4{ }^{\circ} \mathrm{C}$ and $42{ }^{\circ} \mathrm{C}$ in an incubator with the same photoperiod, respectively, for lowand high-temperature stressors. After stress treatments, leaves were sampled at 0, 1, 2, 6, 12 , and $24 \mathrm{~h}$. As controls, leaves sampled at $0 \mathrm{~h}$ were used. Each treatment was replicated biologically three times. After collecting the samples, they were promptly frozen in liquid nitrogen and then stored at $-80{ }^{\circ} \mathrm{C}$ for future analysis.

\subsection{RNA Extraction and Gene Expression Analysis}

A Plant Rneasy Mini Kit (Qiagen, Hilden, Germany) was used to extract total RNA according to the operating instructions. A spectrophotometer (NanoDrop2000, Thermo Scientific, Wilmington, DE, USA) was used to measure the RNA concentration at OD $=260$ and $280 \mathrm{~nm}$, and the threshold standard for $260 / 280 \mathrm{~nm}$ was $1.80-2.20$. A PrimeScript ${ }^{\circledR}$ RT kit (TaKaRa, Dalian, China) was used to synthesize cDNA, following the product manual, and $1 \mu \mathrm{g}$ RNA was used each time to synthesize the first-strand cDNA. Genscript online design software (https:/ / www.genscript.com/tools/pcr-primers-designer, accessed on 16 March 2021) was used to design primer pairs (Table S7). The RT-qPCR was performed with StepOnePlus real-time PCR system (Applied Biosystems, Beijing, China). The qPCR parameters were $10 \mathrm{~min}$ at $95^{\circ} \mathrm{C} ; 15 \mathrm{~s}$ at $95^{\circ} \mathrm{C}, 30 \mathrm{~s}$ at $60^{\circ} \mathrm{C}$, and $30 \mathrm{~s}$ at $72^{\circ} \mathrm{C}$, for 40 cycles; and the melting process was performed at $60-95{ }^{\circ} \mathrm{C}$ to generate a melting curve. The reaction mixture contains $10 \mu \mathrm{L}$ of $2 \times$ SYBR GreenMasterMix (Bimake, TX, USA), $1 \mu \mathrm{L}$ of diluted cDNA, and $0.4 \mu \mathrm{L}$ of forward and reverses primers $(10 \mu \mathrm{M})$. ACT was used as an internal reference gene [39]. Three replicate analyses were performed for each reaction, and then the data was analyzed using the $2^{-\Delta \Delta C T}$ method. Tbtools were used to draw a heat map of $\log _{2}\left(1+2^{-\Delta \Delta C T}\right)$ values. HhbHLH gene expression was analyzed according to the FPKM value of the transcriptome data of the H. hamabo under drought and salt stresses [40], and Tbtools was used to draw a heat map of the $\log _{2}(1+$ FPKM $)$ value.

\subsection{Generation of HhbHLH2 Transgenic Arabidopsis Plants}

The ORF sequence of HhbHLH2 was cloned into the $p C A M B I A 1305$ vector. Then HhbHLH2-1305 was transformed into GV3101, and Arabidopsis thaliana Col-0 was transformed by the inflorescence infection method [41]. The T3 transgenic Arabidopsis was identified by hygromycin $(150 \mathrm{mg} / \mathrm{L})$ selection for subsequent experimental analysis. To treat Arabidopsis thaliana with salt stress and drought, the seeds of the transgenic Arabidopsis and Col-0 (WT) were sterilized and cultured on 1/2 MS medium containing $200 \mathrm{mM}$ 
D-mannitol and $50 \mathrm{mM} \mathrm{NaCl}$. The phenotypes were observed and the root length was measured after 7 days of cultivation at $22{ }^{\circ} \mathrm{C}$.

\section{Conclusions}

Using the HMMER software, we identified 162 HhbHLHs in H. hamabo. Then the $162 \mathrm{HhbHLH}$ genes were split into 19 subfamilies. Gene structure and motif analyses corroborated the phylogenetic analysis results. The cis-elements found in the promoters of the HhbHLHs were found to be associated with phytohormones and abiotic stresses. Transcriptomic profiles and RT-qPCR analysis revealed that $\mathrm{HhbHlH57,} \mathrm{HhbHlH78,} \mathrm{HhbHlH136}$, and $\mathrm{HhbHlH78}$ were significantly up-regulated in response to salt and drought stress. In addition, the overexpression of $\mathrm{HhbHLH} 2$ increased salt and drought stress tolerance in Arabidopsis.

Supplementary Materials: The following are available online at https:/ /www.mdpi.com/article/10 $.3390 / \mathrm{ijms} 22168748 / \mathrm{s} 1$.

Author Contributions: Conceptualization, C.G.; investigation, L.N., Z.W., Z.F. and D.L.; formal analyis, C.G. and L.N.; resources, H.L. and Y.Y.; writing-original draft preparation: C.G. and L.N.; writing-review and editing, C.G., H.L. and L.N. All authors have read and agreed to the published version of the manuscript.

Funding: This work was supported by the Six Talent Peaks Project of Jiangsu Province (NY-042) and the 333 Talents Project of Jiangsu Province (BRA2017498) and the Open Fund of Jiangsu Key Laboratory for the Research and Utilization of Plant Resources (JSPKLB201928).

Institutional Review Board Statement: Not applicable.

Informed Consent Statement: Not applicable.

Conflicts of Interest: The authors declare no conflict of interest.

\section{References}

1. Pruneda-Paz, J.L.; Breton, G.; Nagel, D.H.; Kang, S.E.; Bonaldi, K.; Doherty, C.; Ravelo, S.; Galli, M.; Ecker, J.; Kay, S.A. A GenomeScale Resource for the Functional Characterization of Arabidopsis transcription Factors. Cell Rep. 2014, 8, 622-632. [CrossRef]

2. Ledent, V.; Vervoort, M. The Basic Helix-Loop-Helix Protein Family: Comparative Genomics and Phylogenetic Analysis. Genome Res. 2001, 11, 754-770. [CrossRef]

3. Massari, M.E.; Murre, C. Helix-Loop-Helix Proteins: Regulators of Transcription in Eucaryotic Organisms. Mol. Cell. Biol. 2000, 20, 429-440. [CrossRef] [PubMed]

4. Feller, A.; Machemer, K.; Braun, E.; Grotewold, E. Evolutionary and comparative analysis of MYB and bHLH plant transcription factors. Plant J. 2011, 66, 94-116. [CrossRef]

5. Huang, X.-S.; Wang, W.; Zhang, Q.; Liu, J.-H. A Basic Helix-Loop-Helix Transcription Factor, PtrbHLH, of Poncirus trifoliata Confers Cold Tolerance and Modulates Peroxidase-Mediated Scavenging of Hydrogen Peroxide. Plant Physiol. 2013, 162, 1178-1194. [CrossRef]

6. Ludwig, S.R.; Habera, L.F.; Dellaporta, S.L.; Wessler, S.R. Lc, a member of the maize R gene family responsible for tissue-specific anthocyanin production, encodes a protein similar to transcriptional activators and contains the myc-homology region. Proc. Natl. Acad. Sci. USA 1989, 86, 7092-7096. [CrossRef]

7. Dong, H.; Chen, Q.; Dai, Y.; Hu, W.; Zhang, S.; Huang, X. Genome-wide identification of PbrbHLH family genes, and expression analysis in response to drought and cold stresses in pear (Pyrus bretschneideri). BMC Plant Biol. 2021, 21, 1-20. [CrossRef]

8. Zhou, Z.; Wang, J.; Zhang, S.; Yu, Q.; Lan, H. Investigation of the Nature of CgCDPK and CgbHLH001 Interaction and the Function of bHLH Transcription Factor in Stress Tolerance in Chenopodium glaucum. Front. Plant Sci. 2021, 11, 11. [CrossRef] [PubMed]

9. Qiu, J.-R.; Huang, Z.; Xiang, X.-Y.; Xu, W.-X.; Wang, J.-T.; Chen, J.; Song, L.; Xiao, Y.; Li, X.; Ma, J.; et al. MfbHLH38, a Myrothamnus flabellifolia bHLH transcription factor, confers tolerance to drought and salinity stresses in Arabidopsis. BMC Plant Biol. 2020, 20, 1-14. [CrossRef]

10. Liu, H.; Yang, Y.; Liu, D.; Wang, X.; Zhang, L. Transcription factor TabHLH49 positively regulates dehydrin WZY2 gene expression and enhances drought stress tolerance in wheat. BMC Plant Biol. 2020, 20, 259. [CrossRef]

11. Zuo, Z.-F.; Kang, H.-G.; Hong, Q.-C.; Park, M.-Y.; Sun, H.-J.; Kim, J.; Song, P.-S.; Lee, H.-Y. A novel basic helix-loop-helix transcription factor, ZjICE2 from Zoysia japonica confers abiotic stress tolerance to transgenic plants via activating the DREB/CBF regulon and enhancing ROS scavenging. Plant Mol. Biol. 2020, 102, 447-462. [CrossRef] 
12. Dong, Y.; Wang, C.; Han, X.; Tang, S.; Liu, S.; Xia, X.; Yin, W. A novel bHLH transcription factor PebHLH35 from Populus euphratica confers drought tolerance through regulating stomatal development, photosynthesis and growth in Arabidopsis. Biochem. Biophys. Res. Commun. 2014, 450, 453-458. [CrossRef]

13. Toledo-Ortiz, G.; Huq, E.; Quail, P.H. The Arabidopsis Basic/Helix-Loop-Helix Transcription Factor Family. Plant Cell 2003, 15, 1749-1770. [CrossRef]

14. Pires, N.; Dolan, L. Origin and Diversification of Basic-Helix-Loop-Helix Proteins in Plants. Mol. Biol. Evol. 2010, 27, 862-874. [CrossRef]

15. Li, J.; Wang, T.; Han, J.; Ren, Z. Genome-wide identification and characterization of cucumber bHLH family genes and the functional characterization of CsbHLH041 in NaCl and ABA tolerance in Arabidopsis and cucumber. BMC Plant Biol. 2020, 20, 1-20. [CrossRef]

16. Zhao, W.; Liu, Y.; Li, L.; Meng, H.; Yang, Y.; Dong, Z.; Wang, L.; Wu, G. Genome-Wide Identification and Characterization of bHLH Transcription Factors Related to Anthocyanin Biosynthesis in Red Walnut (Juglans regia L.). Front. Genet. 2021, 12, 632509. [CrossRef]

17. Zhang, Z.; Chen, J.; Liang, C.; Liu, F.; Hou, X.; Zou, X. Genome-Wide Identification and Characterization of the bHLH Transcription Factor Family in Pepper (Capsicum annuum L.). Front. Genet. 2020, 11, 570156. [CrossRef] [PubMed]

18. Nakanishi, H. Distribution and ecology of a semi-mangrove plant, Hibiscus hamabo SIEB. et ZUCC. And its community. Acta Phytotaxon. Geobot. 1979, 30, 169-179.

19. Fowler, E. Assessment and Characterization of Microbial Communities in Salt Affected Soils on Galveston Island. Electronic Theses and Dissertations. 2017, 76. Available online: https://scholarworks.sfasu.edu/etds/76 (accessed on 16 March 2021).

20. Wang, Z.; Xu, X.; Ni, L.; Guo, J.; Gu, C. Efficient virus-induced gene silencing in Hibiscus hamabo Sieb. et Zucc. using tobacco rattle virus. Peer] 2019, 7, e7505. [CrossRef] [PubMed]

21. Carretero-Paulet, L.; Galstyan, A.; Villanova, I.R.; Martinez-Garcia, J.; Bilbao-Castro, J.R.; Robertson, D.L. Genome-Wide Classification and Evolutionary Analysis of the bHLH Family of Transcription Factors in Arabidopsis, Poplar, Rice, Moss, and Algae. Plant Physiol. 2010, 153, 1398-1412. [CrossRef]

22. Gu, Z.; Cavalcanti, A.; Chen, F.-C.; Bouman, P.; Li, W.-H. The extent of gene duplication in the genomes of Drosophila, nematode, and yeast. Mol. Biol. Evol. 2002, 19, 256-262. [CrossRef] [PubMed]

23. Holub, E.B. The arms race is ancient history in Arabidopsis, the wildflower. Nat. Rev. Genet. 2001, 2, 516-527. [CrossRef]

24. Qiao, X.; Li, M.; Li, L.; Yin, H.; Wu, J.; Zhang, S. Genome-wide identification and comparative analysis of the heat shock transcription factor family in Chinese white pear (Pyrus bretschneideri) and five other Rosaceae species. BMC Plant Biol. 2015, 15, 1-16. [CrossRef] [PubMed]

25. Yang, Z. PAML 4: Phylogenetic Analysis by Maximum Likelihood. Mol. Biol. Evol. 2007, 24, 1586-1591. [CrossRef]

26. Liu, W.; Tai, H.; Li, S.; Gao, W.; Zhao, M.; Xie, C.; Li, W. b HLH 122 is important for drought and osmotic stress resistance in $A$ rabidopsis and in the repression of ABA catabolism. New Phytol. 2014, 201, 1192-1204. [CrossRef]

27. Rushton, P.J.; Bokowiec, M.T.; Han, S.; Zhang, H.; Brannock, J.F.; Chen, X.; Laudeman, T.W.; Timko, M.P. Tobacco Transcription Factors: Novel Insights into Transcriptional Regulation in the Solanaceae. Plant Physiol. 2008, 147, 280-295. [CrossRef] [PubMed]

28. Ying, S.; Deming, Z. Existence theorems for a second order three-point boundary value problem with impulses. Appl. Math. 2005, 20, 165-174. [CrossRef]

29. Cannon, S.B.; Mitra, A.; Baumgarten, A.; Young, N.D.; May, G. The roles of segmental and tandem gene duplication in the evolution of large gene families in Arabidopsis thaliana. BMC Plant Biol. 2004, 4, 10. [CrossRef] [PubMed]

30. Yang, Y.-Y.; Zheng, P.-F.; Ren, Y.-R.; Yao, Y.-X.; You, C.-X.; Wang, X.-F.; Hao, Y.-J. Apple MdSAT1 encodes a bHLHm1 transcription factor involved in salinity and drought responses. Planta 2021, 253, 1-13. [CrossRef]

31. El-Gebali, S.; Mistry, J.; Bateman, A.; Eddy, S.R.; Luciani, A.; Potter, S.C.; Qureshi, M.; Richardson, L.J.; Salazar, G.A.; Smart, A.; et al. The Pfam protein families database in 2019. Nucleic Acids Res. 2018, 47, D427-D432. [CrossRef] [PubMed]

32. Eddy, S.R. Accelerated Profile HMM Searches. PLoS Comput. Biol. 2011, 7, e1002195. [CrossRef]

33. Bailey, T.L.; Boden, M.; Buske, F.A.; Frith, M.; Grant, C.E.; Clementi, L.; Ren, J.; Li, W.W.; Noble, W.S. MEME SUITE: Tools for motif discovery and searching. Nucleic Acids Res. 2009, 37, w202-w208. [CrossRef] [PubMed]

34. Guo, A.-Y.; Zhu, Q.H.; Chen, X.; Luo, J.C. GSDS: A gene structure display server. Hereditas 2007, 29, 1023-1026. [CrossRef] [PubMed]

35. Chen, C.; Chen, H.; Zhang, Y.; Thomas, H.R.; Frank, M.H.; He, Y.; Xia, R. TBtools: An Integrative Toolkit Developed for Interactive Analyses of Big Biological Data. Mol. Plant 2020, 13, 1194-1202. [CrossRef]

36. Kumar, S.; Stecher, G.; Tamura, K. MEGA7: Molecular Evolutionary Genetics Analysis Version 7.0 for Bigger Datasets. Mol. Biol. Evol. 2016, 33, 1870-1874. [CrossRef]

37. Tang, H.; Wang, X.; Bowers, J.; Ming, R.; Alam, M.; Paterson, A.H. Unraveling ancient hexaploidy through multiply-aligned angiosperm gene maps. Genome Res. 2008, 18, 1944-1954. [CrossRef] [PubMed]

38. Wang, D.; Zhang, Y.; Zhang, Z.; Zhu, J.; Yu, J. KaKs_Calculator 2.0: A Toolkit Incorporating Gamma-Series Methods and Sliding Window Strategies. Genom. Proteom. Bioinform. 2010, 8, 77-80. [CrossRef]

39. Ni, L.; Wang, Z.; Liu, L.; Guo, J.; Li, H.; Gu, C. Selection and verification of candidate reference genes for gene expression by quantitative RT-PCR in Hibiscus hamabo Sieb.et Zucc. Trees 2019, 33, 1591-1601. [CrossRef] 
40. Wang, Z.; Ni, L.; Hua, J.; Liu, L.; Yin, Y.; Li, H.; Gu, C. Transcriptome Analysis Reveals Regulatory Framework for Salt and Drought Tolerance in Hibiscus hamabo Siebold \& Zuccarini. Forests 2021, 12, 454. [CrossRef]

41. Clough, S.J.; Bent, A. Floral dip: A simplified method forAgrobacterium-mediated transformation of Arabidopsis thaliana. Plant J. 1998, 16, 735-743. [CrossRef] 